\title{
Evaluation of Spirometry for Medical Clearance in Occupations Requiring Respirator Usage
}

\author{
Ushang Desai, Giffe T. Johnson, James D. McCluskey, Raymond D. Harbison \\ Center for Environmental and Occupational Risk Analysis and Management, College of Public Health, \\ University of South Florida, Tampa, USA \\ Email: rharbiso@health.usf.edu
}

How to cite this paper: Desai, U., Johnson, G.T., McCluskey, J.D. and Harbison, R.D. (2017) Evaluation of Spirometry for Medical Clearance in Occupations Requiring Respirator Usage. Occupational Diseases and Environmental Medicine, 5, 67-77. https://doi.org/10.4236/odem.2017.53007

Received: August 15, 2017

Accepted: August 28, 2017

Published: August 31, 2017

Copyright $\odot 2017$ by authors and Scientific Research Publishing Inc. This work is licensed under the Creative Commons Attribution International License (CC BY 4.0).

http://creativecommons.org/licenses/by/4.0/

\begin{abstract}
Medical certification of workers for respirator use is an important activity of occupational medicine health professionals. Spirometry is a diagnostic tool to evaluate respiratory distress/insufficiency that may affect respirator use. The pulmonary function data of 337 subjects from different occupations that required medical evaluation to wear a respirator were analyzed to determine the effect of using various spirometric equations on respirator fitness outcomes. Of 337 subjects who were cleared for respiratory use by medical questionnaires for respirator compliance, $14(4.15 \%)$ failed to pass respirator compliance by NFPA criteria and $5(1.48 \%)$ failed to pass respirator compliance measures by ATS criteria. We compared the use of different spirometric equations to evaluate these measures, and it was determined that the Crapo equation cleared more workers for respirator use as compared to the Knudson and NHANES III equations. As some workers were able to qualify for respirator use based on questionnaire alone but failed respirator clearance after pulmonary function testing, it is recommended that spirometry is used to evaluate clearance for all workers who will use a respirator in the workplace. As well, using different spirometric equations can affect the outcome on passing or failing clearance for respirator use, and this should be considered in a respiratory medical certification program.
\end{abstract}

\section{Keywords}

Spirometry, NHANES III, Crapo, Knudson, Respiratory Protection Program

\section{Introduction}

According to the Occupational Safety \& Health Administration (OSHA), approximately 2.6 million workers use respirators either occasionally or frequently to protect their health in the workplace [1]. Respiratory protection is a last line 
of control measure and is widely used by industries to reduce the risk of airborne chemical exposure [2]. OSHA allows the use of respirators in the workplace when implementations of other control measures are not efficient and pragmatic. To protect workers' health and provide proper guidance regarding respirator use, OSHA requires a respirator protection program in the workplace. In 1998, OSHA revised the criteria for respiratory protection for general industry, shipyards, construction, and maritime industries under 29 CFR 1910 \& 1926 [3]. According to these standards, employers are required to establish a written respiratory protection program when the use of a respirator is mandatory to protect the health of employees in the workplace. It also allows the voluntary use of respirators to prevent exposure to hazardous airborne contaminants. The goals of the respiratory protection program are to provide information on selecting respirators for specific work conditions, a medical evaluation of the workers who are using respirators, and training and maintenance for the respirators used in the workplace [4]. Medical evaluation and certification before respirator use in the workplace is a critical component of the respiratory protection program.

Using respirators in the workplace may induce various physiological and psychological effects on workers [5]. The most common physiological effects from using respirators are cardiopulmonary related [6] [7]. Other effects of using respirators are discomfort, extra weight and ergonomic concerns, psychological and social consequences, dermatological problems, and visual impairments [5] [8]. The physiological effects of respirator use are described in Table 1 [9]-[20]. The purpose of a medical evaluation for respirator certification is to determine employees' ability to wear a respirator before fit testing [21]. Spirometry outcomes provide valuable diagnostic information regarding pulmonary function that may lead to a determination of respirator fitness.

There are, however, some areas of uncertainty regarding the interpretation of spirometry outcomes. Different reference values/equations are available for interpretation of spirometry results. Several regulatory agencies and academic institutions recommended the National Health and Nutritional Survey III (NHANES III) reference equation as this equation included Caucasian, African American, and Hispanic populations to develop reference values, compared to other reference values that are based solely on Caucasian, non-smoking, healthy subjects.

Table 1. Health effects of using respirators [9]-[20].

\begin{tabular}{lll}
\hline \multirow{2}{*}{ Respiratory Effects } & - Increased dead space volumes \\
& - Increases airway resistance \\
\hline \multirow{2}{*}{ Cardiovascular Effects } & - Increased intrathoracic pressure \\
& - Reduces cardiac output \\
\hline & - Heat stress \\
Other Ill-Health Effects & - Dehydration \\
& - Claustrophobia \\
& - Ergonomic health issues \\
& - Dermatological effects \\
\hline
\end{tabular}


As well, there are varying medical criteria that suggest a particular level of pulmonary function will allow a worker to safely use a respirator in the workplace. The American Thoracic Society recommends that employees with $>$ FEV1 of $60 \%$ of predicted value be allowed to wear a respirator [22]; National Fire Protection Agency (NFPA-1582) suggests that any firefighter with FVC or FEV1 < $70 \%$ prevents the safe use of SCBA respirators [23] [24].

The most commonly used and recommended reference values are based on the National Health and Nutrition Examination Survey III (NHANES III) derived by Hankinson et al. 1999. However, spirometric reference equations derived by Crapo et al. (Crapo), Knudson et al. (Knudson) and Morris et al. (Morris) are also currently used in the contemporary interpretation of spirometry outcomes [24] [25] [26] [27].

The purpose of the current study is to evaluate the use of spirometry as a screening tool for pulmonary fitness for respirator usage in the workplace. As well, we evaluate the impact of using different spirometric equations as well as different clearance thresholds of pulmonary function test outcomes on certification of respirator fitness. This study advances the application of spirometry for respirator clearance and demonstrates the impact of criteria selection when performing occupational pulmonary function testing.

\section{Methods}

\subsection{Subject Selection}

This study selected subjects who underwent pulmonary function testing for respirator fitness certification in the boat manufacturing industry, emergency responders, and utility workers in the state of the Florida. Selection of study participants was based on the following criteria:

1) He or she is working in either of the above occupational sectors.

2) Age at or above 18 years.

3) Used a regular respirator in the workplace.

4) Repeatedly conducted spirometry for medical clearance to wear a respirator.

A record review was performed on pulmonary function tests from a population currently employed in above occupation sectors. Of these, 337 workers were identified based on the inclusion criteria. This study was approved by the University of South Florida, Institutional Review Board (IRB) \# 00001348.

\subsection{Statistical Analyses}

Kappa Statistics $(\kappa)$ were used to measure agreement between spirometric results derived from NHANES III, Crapo, and Knudson in meeting the spirometric criteria of the American Thoracic Society and National Fire Protection Association for medical certification for respirator clearance. The Kappa statistic is defined as an interobservation agreement [28]. Kappa statistics are anticipated to provide the reader a quantitative evaluation of the magnitude of agreement between 
observations [29]. Kappa statistics are based on the difference between "observed" agreements to chance agreements ("Expected" agreements) [29] [30]. Kappa statistics for categorical data were interpreted by guidelines suggested by Landis et al. 1977 [31]. The Generalized McNemar's test was used to measure the presence of bias. A p value of $<0.05$ for the hypothesis (H0: $\kappa=0$ ) was considered to be significant.

Interclass correlation coefficients (ICC) are used to evaluate interrater reliability for continuous data. ICC is the assessment of the correlation between two measurements made on the same worker. ICC provides an evaluation of reliability, but many forms of ICC exist, and each is appropriate under limited conditions [32] [33] [34] [35] [36]. In this study ICC was calculated for pulmonary function outcomes such as Forced Expiratory Volume in First Second (FEV1), Forced Vital Capacity (FVC) and the FEV1/FVC ratio derived from the different reference equations Knudson (1983), Crapo (1981) and NHANES III [25] [26]. The potentially confounding factors age, gender, smoking history, weight, and height are included in the statistical analysis.

All statistical analyzes were conducted using SAS 9.4 software package.

\section{Results}

The demographics of the study population are described in Table 2. The study

Table 2. Study population demographics.

\begin{tabular}{|c|c|c|}
\hline Total Number & 337 & $100 \%$ \\
\hline \multicolumn{3}{|l|}{ Gender } \\
\hline Male & 296 & $87.83 \%$ \\
\hline Female & 41 & $12.16 \%$ \\
\hline \multicolumn{3}{|l|}{ Smoking History } \\
\hline Yes & 120 & $35.61 \%$ \\
\hline No & 217 & $64.39 \%$ \\
\hline \multicolumn{3}{|l|}{ Race } \\
\hline Caucasian & 282 & $83.68 \%$ \\
\hline African-American & 24 & $7.12 \%$ \\
\hline Hispanic & 31 & $9.20 \%$ \\
\hline \multicolumn{3}{|l|}{ Occupations } \\
\hline Boat Manufacturing & 122 & $36.20 \%$ \\
\hline First Responders & 129 & $38.28 \%$ \\
\hline Utility Workers & 86 & $25.52 \%$ \\
\hline \multicolumn{3}{|l|}{ Age } \\
\hline$\leq 54$ years old & 307 & $91.10 \%$ \\
\hline$\geq 55$ years old & 30 & $8.90 \%$ \\
\hline
\end{tabular}


population was primarily male (approximately 87\%), mainly Caucasian (approximately $83 \%$ ) and about $35 \%$ had a smoking history. The average age of the study population is 40 years, and the average height of the population is 69 inches.

\subsection{National Fire Protection Association (NFPA) Criteria}

This study used the NFPA spirometry criteria (FEV1 or FVC $\geq 70$ ) for screening fitness to wear respirators in the workplace. Table 3 and Table 4 indicate the summary of subjects who met the spirometry criteria stratified by spirometric reference equations. A small number of subjects with FEV1 (14, 4.15\%) and FVC $(9,2.67 \%)$ were not able to pass the spirometry screening criteria despite having passed the OSHA recommended questionnaire.

\subsection{American Thoracic Society Criteria}

This study also applied the criteria (FEV1 $\geq 60$ ) recommended by the American Thoracic Society for screening purposes to wear respirators. A small percentage of the subjects who had been cleared by the OSHA approved questionnaire failed to pass the selection criteria to wear respirators. Table 5 presents the number of subjects who failed to meet standards recommended by the ATS.

Table 3. Number of workers who met the national fire protection association (FEV1) criteria to wear respirators.

\begin{tabular}{ccc}
\hline \multicolumn{3}{c}{ FEV1 $\geq 70$ (Total Number $=337)$} \\
Pass & Fail \\
\hline NHANES III (1999) & $323(95.84 \%)$ & $14(4.15 \%)$ \\
Crapo et al. 1981 & $318(94.36 \%)$ & $19(5.63 \%)$ \\
Knudson et al. 1983 & $322(95.54 \%)$ & $15(4.45 \%)$
\end{tabular}

Table 4. Number of workers who met the national fire protection association (FVC) criteria to wear respirators.

\begin{tabular}{ccc}
\hline \multicolumn{3}{c}{ FVC $\geq 70$ (Total Number $=337)$} \\
Pass & Fail \\
\hline NHANES III (1999) & $328(97.32 \%)$ & $9(2.67 \%)$ \\
Crapo et al. 1981 & $325(96.43 \%)$ & $12(3.5 \%)$ \\
Knudson et al. 1983 & $330(97.92 \%)$ & $7(2.07 \%)$ \\
\hline
\end{tabular}

Table 5. Number of workers who met the American thoracic criteria to wear respirators.

\begin{tabular}{ccc}
\hline \multicolumn{3}{c}{ FEV1 $\geq 60$ (Total Number $=337)$} \\
\hline \\
Pass & Fail \\
\hline NHANES III (1999) & $332(98.51 \%)$ & $5(1.48 \%)$ \\
Crapo et al. 1981 & $330(97.92 \%)$ & $7(2.07 \%)$ \\
Knudson et al. 1983 & $331(98.21 \%)$ & $6(1.78 \%)$ \\
\hline
\end{tabular}


Figure 1 outlines the comparison of different spirometric criteria used to certify "suitable to wear a respirator" in various occupations.

\subsection{Agreement between NHANES III and Crapo Reference Equations}

This study analyzed 337 subjects using the NHANES III and the Crapo reference equations to compare the spirometry compliance criteria [24] [26]. For comparing the various compliance criteria, the level of agreement between the NHANES III reference standard with the Crapo reference standard is varied from good ( $\kappa$ $=0.76)$ to very good $(\kappa=0.85)$ as shown in Table 6 .

\subsection{Agreement between the NHANES III and the Knudson Reference Standards}

To compare the spirometry compliance criteria, the study analyzed the 337 workers using the NHANES III and the Knudson reference equations [24] [25]. For comparing the various compliance criteria, the level of agreement between the NHANES III reference standard and the Knudson reference standard is very good ( $\kappa=0.83$ to 0.96$)$ as shown in Table 7.

\subsection{Interclass Correlation Coefficient}

In this study, interpretation of lung function of workers using different spirometry reference standards was utilized. An ICC was calculated for these different reference standards for the assessment of lung functions and interclass correlation coefficient are shown in Table 8.
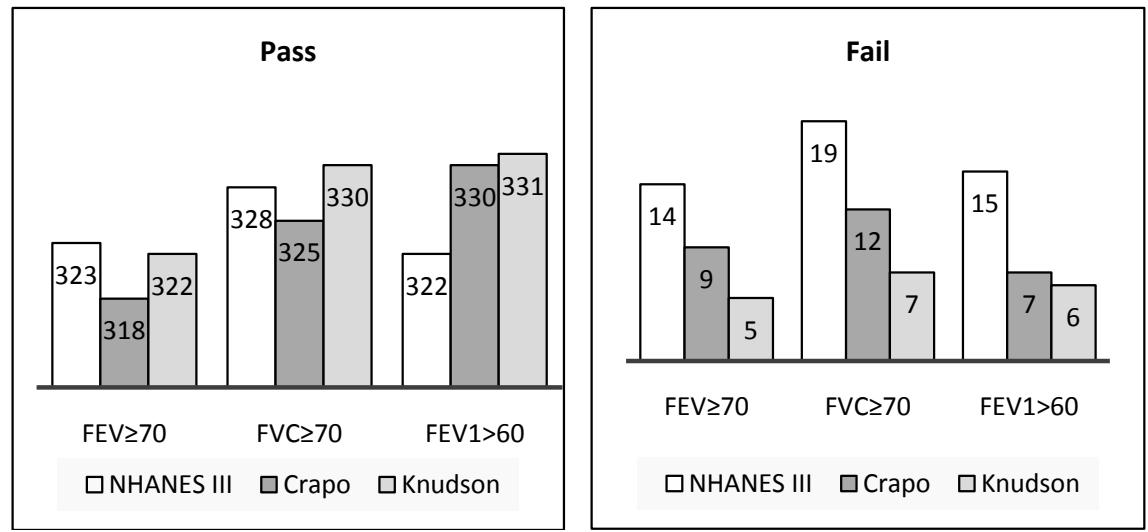

Figure 1. Comparison of different spirometric criteria to wear respirators.

Table 6. Agreement between the NHANES III and the crapo standards for the respirator screening criteria.

\begin{tabular}{cccc}
\hline Compliance Criteria & Kappa Statistics* & $\begin{array}{c}\text { Generalized } \\
\text { McNemar's Test }\end{array}$ & p-Value \\
\hline NFPA Criteria (FEV1 $<70)$ & $0.8409(0.7042-0.9775)$ & $\mathrm{p}=0.0253$ & $\mathrm{P}<0.001$ \\
NFPA Criteria $(\mathrm{FVC}<70)$ & $0.8526(0.6885-1.00)$ & $\mathrm{p}=0.0833$ & $\mathrm{P}<0.001$ \\
ATS Criteria $($ FEV1 $>60)$ & $0.8304(0.5994-1.00)$ & $\mathrm{p}=0.1533$ & $\mathrm{P}<0.001$ \\
\hline
\end{tabular}


Table 7. Agreement between the NHANES III and the Knudson reference standards for the respirator screening criteria.

\begin{tabular}{cccc}
\hline Compliance Criteria & Kappa Statistics & Generalized McNemar's Test & $\mathrm{p}$-value \\
NFPA Criteria $($ FEV1 $<70)$ & $0.96(0.89-1.00)$ & $\mathrm{p}=0.3173$ & $\mathrm{p}<0.001$ \\
NFPA Criteria $(\mathrm{FVC}<70)$ & $0.87(0.69-1.00)$ & $\mathrm{p}=0.1573$ & $\mathrm{p}<0.001$ \\
ATS Criteria $(\mathrm{FEV} 1>60)$ & $0.90(0.72-1.00)$ & $\mathrm{p}=0.3173$ & $\mathrm{p}<0.001$ \\
\hline
\end{tabular}

Table 8. Interclass correlation coefficients (ICC) for different reference standards (NHANES III vs. Knudson vs. Crapo reference standards).

\begin{tabular}{cc}
\hline Lung Functions & Interclass Correlation Coefficient (ICC) \\
\hline FEV1 & 0.27783 \\
FVC & 0.87452 \\
FEV1/FVC Ratio & 0.80436 \\
\hline
\end{tabular}

\section{Discussion}

This study evaluates the use of spirometry as a screening tool in addition to the OSHA recommended questionnaire for clearance to wear respirators in the workplace. A small percentage of workers (4.15\%, 2.67\% and 1.48\%) failed the spirometry criteria to wear a respirator provided by NFPA (FEV1 and FVC) and ATS (FEV1), respectively. These subjects had passed the OSHA recommended questionnaire, indicating that the OSHA recommended questionnaire did not identify a small percentage of subjects who may not be healthy enough to wear a respirator.

Though OSHA allows the use of a questionnaire for respiratory protection program compliance, physical examination and screening tools such as spirometry help to identify workers who are at risk for cardiopulmonary stress as well as mortality, currently, there are no broadly standardized regulations available for spirometry criteria nor is there a requirement for the inclusion of screening with spirometry in a respiratory protection program. Other factors, such as a type of respirator use, work conditions and heat, and other stressors while screening for respirator use should be considered.

The American Thoracic Society/European Respiratory Society in 2005 recommended use of the NHANES III reference standards to diagnose occupational lung diseases in the United States, although it suggested that other reference standards may be utilized if there are valid reasons for the choice of these standards [27]. Alternative respiratory reference standards are used in certain mandatory conditions such as the requirement to use the Knudson 1976 standard in the cotton industry. The contemporary use of older spirometry reference standards could potentially impact the interpretation of pulmonary function tests for diagnosis and respiratory clearance.

However, the kappa statistics for the NFPA compliance criteria is very good between the NHANES III and the Crapo standards while ATS criteria have kap- 
pa statistics in the range of good agreement between the NHANESIII and the Crapo standards. The agreement between these two measures is higher because they are used for screening purposes of wearing a respirator as compared to diagnostic purposes. These results suggest that using either of the reference standards does not largely affect the outcome of the spirometry screening for respirator protection use. The results of this study indicate that decreasing the spirometric criteria to wear a respirator causes more discordance between the two reference standards. Similarly, the kappa statistics for the NFPA compliance criteria and the ATS criteria is very good for the NHANES III and the Knudson standards. This agreement suggests that using the Knudson equation for respiratory compliance measures did not have substantial impact on passing the tests. Interclass correlation coefficients, as discussed above, are the relative measurement of the reliability of the research data. It is a ratio of variance derived from ANOVA [37] [38]. It is unitless and theoretically it is more similar to a R2 from regression models as compared to a Pearson coefficient $(r)$ [39]. The ICC can theoretically range from 0 to 1 , where 0 shows no reliability, whereas 1.0 suggests perfect reliability [38]. The ICC can extend beyond the ranges of 0 to 1.0, but it is uncommon [40].

The ICC for interpretation of FEV1 between the three reference standards is 0.27 ; this suggests that there may not be significant repeatability for the analysis of FEV1 outcomes. However, the ICC for FVC was 0.87 , suggesting good reproducibility between these standards. For the FEV1/FVC ratio, the ICC is 0.80 , suggesting that there is good reproducibility between these standards for the interpretation of lung function. It clearly indicated that assessment of pulmonary function using different reference standards may affect the outcome of occupational lung disease diagnosis.

The major limitation of this study is that investigators did not have access to medical data for the subjects to establish pulmonary diseases among those workers who produced lower pulmonary function outcomes. Future studies should consider the impact of using different reference equations on diagnostic accuracy.

\section{Conclusion}

The results of this study suggest that the use of spirometry as a screening tool is necessary to identify workers who may be unfit to wear a respirator, but have passed the OSHA questionnaire. While overall, there is a good agreement among various pulmonary function reference sets in establishing clearance to wear respirators, which are subtle differences, particularly for the FEV1 outcome. It is recommended that the NHANES III reference set be used when possible due the larger and more diverse reference population.

\section{Acknowledgements}

The authors would like to thank OPHSS Inc. for providing the pulmonary func- 
tion test records used in this study.

\section{References}

[1] (OSHA) OSHA (1994) Respiratory Protection, 29 CFR 1910, 1915, 1926. Government Publishing Office, Washington, DC.

[2] Cohen, H.J. and Birkner, J.S. (2012) Respiratory Protection. Clinics in Chest Medicine, 33, 783-793. https://doi.org/10.1016/j.ccm.2012.09.005

[3] (OSHA) OSHA (1998) Respiratory Protection, 29 CFR 1910, 1926. Federal Register, 63, 1152-1300.

[4] Health OSa and (OSHA) A (2009) Respiratory Protection, CFR, Title 29 Part 1910. Government Publishing Office, Washington DC, 134.

[5] Szeinuk, J., Beckett, W.S., Clark, N. and Hailoo, W.L. (2000) Medical Evaluation for Respirator Use. American Journal of Industrial Medicine, 37, 142-157. https://doi.org/10.1002/(SICI)1097-0274(200001)37:1<142::AID-AJIM11>3.0.CO;2$\underline{\mathrm{K}}$

[6] Louhevaara, V.A., Tuomi, T., Korhonen, O. and Jaakkola, J. (1984) Cardiorespiratory Effects of Respiratory Protective Devices during Exercise in Well-Trained Men. European Journal of Applied Physiology, 52, 340-345. https://doi.org/10.1007/BF01015224

[7] Louhevaara, V.A. (1984) Physiological Effects Associated with the Use of Respiratory Protective Devices. A Review. Scandinavian Journal of Work, Environment \& Health, 10, 275-281. https://doi.org/10.5271/sjweh.2327

[8] Belafsky, S., Vlach, J. and McCurdy, S.A. (2013) Cardiopulmonary Fitness and Respirator Clearance: An Update. Journal of Occupational and Environmental Hygiene, 10, 277-285. https://doi.org/10.1080/15459624.2013.774631

[9] Hermansen, L., Vokac, Z. and Lereim, P. (1972) Respiratory and Circulatory Response to Added Air Flow Resistance during Exercise. Ergonomics, 15, 15-24. https://doi.org/10.1080/00140137208924403

[10] Raven, P.B., Dodson, A.T. and Davis, T.O. (1979) The Physiological Consequences of Wearing Industrial Respirators: A Review. American Industrial Hygiene Association Journal, 40, 517-534. https://doi.org/10.1080/15298667991429912

[11] Raven, P.B. (1984) Medical Evaluation for Respirator Use. Journal of Occupational \& Environmental Medicine, 26, 495-502.

[12] Raven, P.B., Davis, T.O., Safer, C.L. and Linnebur, A.C. (1977) Maximal Stress Test Performance While Wearing a Self-Contained Breathing Apparatus. Journal of Occupational \& Environmental Medicine, 19, 802-806. https://doi.org/10.1097/00043764-197712000-00005

[13] Hodous, T.K. (1986) Screening Prospective Workers for the Ability to Use Respirators. Journal of Occupational \& Environmental Medicine, 28, 1074-1080. https://doi.org/10.1097/00043764-198610000-00031

[14] Kraut, A. (1988) Industrial Respirators: Certifying the Worker. American Family Physician, 37, 117-126.

[15] Morgan, W.P. (1983) Psychological Problems Associated with the Wearing of Industrial Respirators: A Review. American Industrial Hygiene Association Journal, 44, 671-677. https://doi.org/10.1080/15298668391405544

[16] DuBois, A.B., Harb, Z.F. and Fox, S.G. (1990) Thermal Discomfort of Respiratory Protective Devices. American Industrial Hygiene Association Journal, 51, 550-554. 
https://doi.org/10.1080/15298669091370086

[17] American Thoracic Society (1996) Respiratory Protection Guidelines. American Journal of Respiratory and Critical Care Medicine, 154, 1153-1165.

[18] Zelnick, S.D., McKay, R.T. and Lockey, J.E. (1994) Visual Field Loss While Wearing Full-Face Respiratory Protection. American Industrial Hygiene Association Journal, 55, 315-321. https://doi.org/10.1080/15428119491018952

[19] Nielsen, R., Gwosdow, A.R., Berglund, L.G. and DuBois, A.B. (1987) The Effect of Temperature and Humidity Levels in a Protective Mask on User Acceptability during Exercise. American Industrial Hygiene Association Journal, 48, 639-645. https://doi.org/10.1080/15298668791385336

[20] James, R., Dukes-Dobos, F. and Smith, R. (1984) Effects of Respirators under Heat/Work Conditions. American Industrial Hygiene Association Journal, 45, 399-404. https://doi.org/10.1080/15298668491400016

[21] (NIOSH) NIFOSAH (2003) NIOSH Spirometry Training Guide. Morgantown, West Virginia.

[22] Harber, P., Barnhart, S., Boehlecke, B.A., Beckett, W.S., Gerrity, T., McDiarmid, M.A., et al. (1996) Respiratory Protection Guidelines. American Journal of Respiratory and Critical Care Medicine, 154, 1153-1165. https://doi.org/10.1164/ajrccm.154.4.8887621

[23] NFPA $(1986,1989)$ NFPA 1404: Standard for Fire Service Respiratory Protection Training. NFP Association.

[24] Hankinson, J.L., Odencrantz, J.R. and Fedan, K.B. (1999) Spirometric Reference Values from a Sample of the General US Population. American Journal of Respiratory and Critical Care Medicine, 159, 179-187. https://doi.org/10.1164/ajrccm.159.1.9712108

[25] Knudson, R.J., Slatin, R.C., Lebowitz, M.D. and Burrows, B. (1976) The Maximal Expiratory Flow-Volume Curve. Normal standards, Variability, and Effects of Age. American Review of Respiratory Disease, 113, 587-600.

[26] Crapo, R.O., Morris, A.H. and Gardner, R.M. (1981) Reference Spirometric Values Using Techniques and Equipments That Meet ATS Recommendations. American Review of Respiratory Disease, 123, 659-684.

[27] Pellegrino, R., Viegi, G., Brusasco, V., Crapo, R.O., Burgos, F., Casaburi, R., et al. (2005) Interpretative Strategies for Lung Function Tests. European Respiratory Journal, 26, 948-968. https://doi.org/10.1183/09031936.05.00035205

[28] Cohen, J. (1960) A Coefficient of Agreement for Nominal Scales. Educational and Psychological Measurement, 20, 37-46. https://doi.org/10.1177/001316446002000104

[29] Viera, A.J. and Garrett, J.M. (2005) Understanding Interobserver Agreement: The Kappa Statistic. Family Medicine, 37, 360-363.

[30] Sood, A., Dawson, B.K., Henkle, J.Q., Hopkins-Price, P. and Quails, C. (2007) Effect of Change of Reference Standard to NHANES III on Interpretation of Spirometric "Abnormality". International Journal of Chronic Obstructive Pulmonary Disease, 2, 361-367.

[31] Landis, J.R. and Koch, G.G. (1977) The Measurement of Observer Agreement for Categorical Data. Biometrics, 33, 159-174. https://doi.org/10.2307/2529310

[32] Shrout, P.E. and Fleiss, J.L. (1979) Intraclass Correlations: Uses in Assessing Rater Reliability. Psychological Bulletin, 86, 420-428.

https://doi.org/10.1037/0033-2909.86.2.420 
[33] Winer, J.B. (1971) Statistical Principles in Experimental Design. McGraw-Hill, New York.

[34] Group USC (2014) Introduction to SAS. http://www.ats.ucla.edu/stat/sas/code/intraclass.htm

[35] Knudson, R.J., Lebowitz, M.D., Holberg, C.J. and Burrows, B. (1983) Changes in the Normal Maximal Expiratory Flow-Volume Curve with Growth and Aging. American Review of Respiratory Disease, 127, 725-734.

[36] Li, L. and Nawar, S. (2007) Reliability Analysis: Calculate and Compare Intra-Class Correlation Coefficients (ICC) in SAS. Northeast SAS Users Group.

[37] Chinn, S. and Burney, P.G. (1987) On Measuring Repeatability of Data from Self-Administered Questionnaires. International Journal of Epidemiology, 16, 121-127. https://doi.org/10.1093/ije/16.1.121

[38] Weir, J.P. (2005) Quantifying Test-Retest Reliability Using the Intraclass Correlation Coefficient and the SEM. Journal of Strength and Conditioning Research, 19, 231-240.

[39] Rousson, V., Gasser, T. and Seifert, B. (2002) Assessing Intrarater, Interrater and Test-Retest Reliability of Continuous Measurements. Statistics in Medicine, 21, 3431-3446. https://doi.org/10.1002/sim.1253

[40] Lahey, M.A., Downey, R.G. and Saal, F.E. (1983) Intraclass Correlations: There's More Than Meets the Eye. Psychological Bulletin, 93, 586-595.

https://doi.org/10.1037/0033-2909.93.3.586

\section{Submit or recommend next manuscript to SCIRP and we will provide best} service for you:

Accepting pre-submission inquiries through Email, Facebook, LinkedIn, Twitter, etc. A wide selection of journals (inclusive of 9 subjects, more than 200 journals)

Providing 24-hour high-quality service

User-friendly online submission system

Fair and swift peer-review system

Efficient typesetting and proofreading procedure

Display of the result of downloads and visits, as well as the number of cited articles

Maximum dissemination of your research work

Submit your manuscript at: http://papersubmission.scirp.org/

Or contact odem@scirp.org 